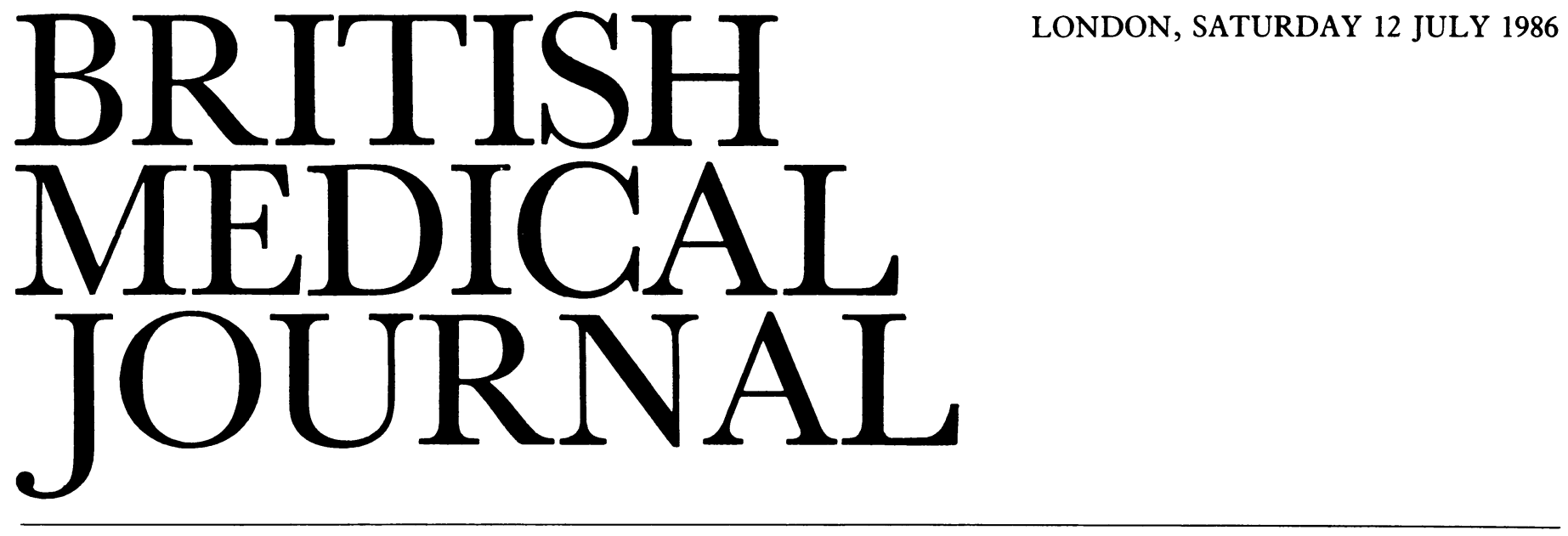

\title{
A promising package on hospital staffing
}

If there were a simple solution to the problems of medical manpower in the hospital service that would please both those doctors in established posts and those in training it would have been found already. Proposals and reports have been devised, discussed, and shelved for the past 20 yearsbut time has now run out.' ${ }^{1}$ The combination of restrictions on the entry and registration of doctors from overseas, the cuts affecting academic medicine, and the freezing of posts at all levels by health authorities trying to balance their budgets has sharpened the awareness of young doctors of their shrinking prospects of achieving their ambitions.

Against that background the recommendations of a working group representing the Department of Health and Social Security, the Joint Consultants Committee, and regional health authority chairmen, headed by the Minister for Health, Mr Barney Hayhoe, Mr A H Grabham, and Sir Gordon Roberts (see p 148), will be studied closely by all concerned. The report represents a genuine attempt to find a practical solution, and Mr Grabham deserves our thanks for attempting a task which his many distinguished predecessors found thankless. Inevitably in the climate of the times the proposals will be viewed with great suspicion both by doctors in training (for both the hospital service and general practice) and by consultants in post who will fear "dilution" and loss of supporting staff. Nevertheless, many of the proposalsdescribed by $\mathrm{Mr}$ Grabham as "a series of small steps" (p 152)-will undoubtedly be welcomed, for example, the proposals for voluntary early retirement and for part retirement by consultants and the boost to consultant expansion.

The controversial sections of the report are those which propose a "new non-training intermediate level service grade" with entry from the senior house officer grade, a reduction in registrar posts (to relate their numbers to the number of consultant level appointments), and lengthening of the time doctors may expect to spend as senior house officers. Doctors who accept advice given as career counselling and move into the new grade will, in effect, have accepted that they will never become consultants (though they may eventually be regraded as associate specialists). How does this concept measure up against the standard objections to the concept of a subconsultant career grade? Inevitably, moreover, several important questions will be asked, the answers to which may be crucial in the forthcoming debates.

Firstly, what about clinical autonomy? Will doctors in the new grade be answerable to a consultant or will they be self monitoring? Those with memories of the senior hospital (C) BRITISH MEDICAL JOURNAL 1986. All reproduction rights reserved. medical officer (SHMO) grade will remember the conflicts that arose; someone who has run a clinic for a decade is likely to believe-with justification-that he or she should be trusted to get on with the job.

Secondly, what about training? Is entry to the grade to be made by default - failure to obtain a training registrarship? If so how can patients be reassured that all those appointed have proved their competence?

Thirdly - and this may prove crucial-how irrevocable is the categorisation "subconsultant"? Many young doctors (especially women with children) go through a period of domestic pressure and may opt for a job offering stability; but will they or other doctors who enter this grade be content to remain forever in it?

In many other countries the crucial hurdle is registration as a specialist; once that status has been achieved the individual doctor may choose to work in an outpatient clinic, or on a sessional basis, but always has the freedom to aspire to further training and to competition for more prestigious jobs. In a British setting specialist registration (giving a right to clinical autonomy) might be seen as an intermediate stage through which doctors might pass en route to a consultantship or in which they might choose to stay. The problem with that concept, however, is that politicians might see it as a way of expanding the consultant grade on the cheap. Every gambit has its response.

Without doubt the working group's formula will be criticised and each group of doctors will argue for its preferred alternative. Although the working group looked specifically at the manpower position in England, the Minister for Health has stated that the principles in the package would apply throughout the United Kingdom (p 147). What doctors should try to do is to recognise the reasons why reform is now so urgent. If nothing is done to balance training grades with career posts the hardships and injustices will proliferate and government and health authorities may well take unilateral action to resolve them. In some way the numbers of career posts must be increasedfaster than any likely rate of expansion of the consultant grade. General practice, which in any case has its own training scheme, cannot absorb all surplus hospital doctors and emigration no longer offers an outlet for frustrated young doctors. So the answer must be a new career grade-and there isn't one with attributes that will satisfy everyone.

At their special meetings the Central Committee for Hospital Medical Services and the Hospital Junior Staff Committee acknowledged the urgency of finding an agreed 
solution. Recognising that this opportunity might well not occur again they welcomed and endorsed the proposals, commending them to their constituents for detailed comment. In his addresses to the committees Mr Grabham, who paid tribute to the Minister for Health's initiative in setting up the group and to his colleagues on it, emphasised the importance of accepting the general thrust of the proposals: the details could be negotiated once the principles had been accepted. Moreover, the proposals would take 10 to 15 years to reach maturity, the aim was to balance the numbers of graduating doctors with career opportunities, and all parties in the discussions had made concessions_-a crucial one being to block the clinical assistant loophole by confining these posts to fewer than six sessions.

The two committees showed their political maturity in their willingness to endorse the proposals, their members acting in their true capacity as representatives and not delegates. Some members of the HJSC were worried about taking such a momentous decision without first referring back to their constituents, but a proposal to do this was overwhelmingly defeated. Clearly the great majority of members of the CCHMS and the HJSC felt that having debated manpower ad nauseam for 30 years or more they knew sufficient about the subject to come to a prompt and considered decision. On one important point, the BMA's opposition to a new subconsultant grade, Mr James Kyle, chairman of the representative body, reassured both meetings that in his view the new grade was not a subconsultant one in the sense that the representative body had debated it.

The government will have announced these proposals in parliament by the time this issue of the $B M \mathcal{F}$ is published, and the conference of royal colleges and the JCC will be discussing them shortly. If all parties can agree to proceed with discussions on this promising package of manpower proposals 1 January 1987, the planned time of introduction, may well go down as the day when the hospital doctors' tangled career structure at last began to form a coherent pattern. The initiative is both timely and welcome.

1 Parkhouse J. Manpower: compendium of deliberate mistakes. Br Med f 1986;292:1286-7.

\section{Managing Raynaud's phenomenon}

Although more than 100 years have passed since Maurice Raynaud first described his phenomenon its management strategies are still poorly defined. Recent editions of major textbooks are helpful only in dealing with more severe cases. ${ }^{1}$ Advances in our understanding of some of the pathophysiological processes in vascular disease, platelet behaviour, and blood rheology have created renewed interest in the disorder, however, and opened up possibilities of new approaches to treatment. Raynaud's phenomenon may be a symptom of a serious underlying disorder, such as systemic sclerosis or other connective tissue disorder, or-much more commonly -may present only as vasospasticity of the digits, sometimes also affecting the tip of the nose, tongue, or ears. This latter, primary form may be disabling but is rarely accompanied by complications such as tissue loss which are seen in the secondary form.
The management of primary Raynaud's phenomenon is firstly a task of educating patient and doctor about commonsense approaches to keeping warm. This may need to be backed up by treatment with relatively non-toxic drugs acting on the vascular system and possibly by attempts to improve the circulation with antiplatelet drugs or with drugs affecting red cell filterability.

Specific calcium channel antagonists-particularly nifedipine, verapamil, and diltiazem-have been reported to be effective in several studies. ${ }^{2-7}$ Some of these have included patients with both primary and secondary Raynaud's phenomenon; at Southampton we have studied mainly patients with primary Raynaud's phenomenon and confirmed the value of drugs of this class ( $D$ Waller and colleagues, unpublished data). Different calcium antagonists may act preferentially on different parts of the cardiovascular system, and this may need to be taken into account in choosing the drug, nor is there a uniform dosage regimen, but our experience suggests a range of 5-20 mg of nifedipine or 10-20 mg of its slow acting form. The side effects from this treatment are considerable-flushing, headaches, and ankle oedema - and may be enough to make it unacceptable.

Other vasodilator drugs, such as the nicotinic acid derivatives and oxpentifylline, are probably not as effective as the calcium antagonists.

Another group of drugs which may be useful are those which inhibit thromboxane synthetase or promote antiplatelet vasodilator effects, such as prostaglandin $E_{2}$ or its analogues. This line of treatment has been shown to be effective in patients with quite severe Raynaud's phenomenon, especially in cases where digits or even limbs appear to be at risk. ${ }^{8-10}$ Dazoxiben-a thromboxane synthetase inhibitor-has been reported to correct the increased concentrations of $\beta$ thromboglobulin reported in Raynaud's phenomenon; it does not affect the platelet factor 4 concentration, which tends to be normal anyhow. ${ }^{11}$ These results support the theory that platelet activation in vivo may be part of the mechanism causing the local effects in Raynaud's phenomenon. The problem with some of these drugs has been the need to give them by intra-arterial or intravenous infusion-as has also been the case with ketanserin, a 5-hydroxytryptamine receptor antagonist. ${ }^{12}$ Both ketanserin and dazoxiben, however, are becoming available in oral form. ${ }^{13}$

Other vasodilatory manoeuvres are being investigated, including the application of topical nitroglycerin ointment and transdermal prostaglandin analogues. ${ }^{14} 15$

Sympathectomy has been carried out for treatment of 을 Raynaud's phenomenon, but a questionnaire based study $N$ from the Dulwich Hospital reported in the Raynaud's Association Newsletter showed that the long term benefits were disappointing. ${ }^{16}$ Plasmapheresis has also been recorded as being of value, but it seems to have been superseded by more specific treatment. Biofeedback techniques have been reported to be useful. ${ }^{17}$ The criticisms of early trials of such techniques may well have been answered by more recent reports of sustained improvement on follow up. ${ }^{18}$

Probably many patients with primary Raynaud's phenomenon may benefit from slow calcium channel antagonists, but they may have to wait for new drugs - those currently available were designed mainly for other cardiovascular effects. Similarly newer developments in the category of thromboxane synthetase antagonists are also likely to become available as oral preparations. Patients with the more severe -usually secondary-forms of Raynaud's phenomenon may continue to require more aggressive treatment with

\section{.}

